\title{
AA7075 Yaşlandırılmasında Farklı Ön Gerinmelerin Mekanik Özelliklere Etkilerinin İncelenmesi
}

\author{
Investigation of Effects of Different Pre-straining on Mechanical Properties of AA7075 Aging
}

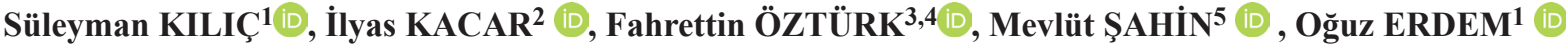 \\ ${ }^{1}$ Kırşehir Ahi Evran Üniversitesi, Mühendislik Mimarlık Fakültesi, Makine Mühendisliği Bölümü \\ ${ }^{2}$ Niğde Ömer Halisdemir Üniversitesi, Mühendislik Fakültesi, Mekatronik Mühendisliği Bölümü \\ ${ }^{3}$ Ankara Yıldırım Beyazıt Üniversitesi, Mühendislik ve Doğa Bilimleri Fakültesi, Makine Mühendisliği Bölümü \\ ${ }^{4}$ TUSAŞ - Türk Havacilı ve Uzay Sanayii AŞ \\ ${ }^{5}$ Niğge Ömer Halisdemir Üniversitesi, Teknik Bilimler Meslek Yüksekokulu
}

$\ddot{O} \mathbf{z}$

Bu çalışmada havacılık sanayinde yaygın kullanıma sahip 7075 alüminyum alaşımının yaşlandırılmasında farklı ön gerinmelerin alaşımın mekanik özelliklerine etkileri incelenmiştir. Çalışmadaki temel amaç farklı oranlarda ön şekillendirilmiş yapısal parçaların boya fırınlaması esnasındaki mekanik ve mikroyapı özelliklerinin değişiminin belirlenmesidir. Boya firınlama işlemlerinde genellikle $120-200{ }^{\circ} \mathrm{C}$ sıcaklıkları kullanılmaktadır. Bu kapsamda çalışmamızda yaşlandırma sıcaklıkları 120, 160 ve $200{ }^{\circ} \mathrm{C}$ olarak seçilmiştir. Numunelere farklı ön gerinmeler uygulanarak ön gerinmenin yaşlandırmadaki etkisi detaylı olarak incelenmiştir. İncelemeler sonucunda ön gerinmenin artmasıyla, $200{ }^{\circ} \mathrm{C}$ yaşlandırma sıcaklığında akma mukavemeti ve geri esneme düşerken, altındaki yaşlandırma sıcaklıklarında artmaktadır. Bunun sebebi ise mikroyapıdaki $\mathrm{MgZn}_{2}$ katı çökeltilerinin hacimsel miktarıdır.

Anahtar Kelimeler: Ön gerinme, $\mathrm{MgZn}_{2}$ katı çökeltileri, AA 7075, mekanik özellikler, XRD, boya firınlama.

\begin{abstract}
In this study, effects of different pre-straining on mechanical properties of AA7075 aging are investigated. The alloy has been widely used in aerospace industry. The purpose of this study is to determine changes in mechanical and microstructural properties of different level pre-deformed structural parts during the paint baking process. The paint baking process is generally performed between 120 and $200{ }^{\circ} \mathrm{C}$. In this concept, aging temperatures of 120,160 and $200^{\circ} \mathrm{C}$ are selected. Different pre-straining is applied on samples to investigate the effects of pre-straining on the aging in detail. Although yield strength and springback are decreased at $200{ }^{\circ} \mathrm{C}$ aging with increasing the pre-straining, they are increased below aging temperatures of $200{ }^{\circ} \mathrm{C}$. The reason is that the increase in volume of $\mathrm{MgZn}_{2}$ solid precipitates in the microstucture.
\end{abstract}

Keywords: Pre-straining, $\mathrm{MgZn}_{2}$ precipitates, AA 7075, mechanical properties, XRD, paint baking.

\section{GİRIŞ̧}

7XXX serisi alüminyum alaşımları sahip oldukları mükemmel mekanik özellikleri nedeniyle havacılık ve uzay sanayinde yoğunlukla tercih edilmektedir [1]. Al-Zn-Mg-Cu alaşımı olarak ta bilinen $7 \mathrm{XXX}$ seri alüminyum alaşımlarında ikincil faz olarak $\left.\eta_{(\mathrm{MgZn}}\right), T$ $\left(\mathrm{Al}_{2} \mathrm{Mg}_{3} \mathrm{Zn}_{3}\right), S\left(\mathrm{Al}_{2} \mathrm{CuMg}\right)$ fazları bulunmaktadır [2-6]. Bu alaşım serisinde faz dönüşümleri;

- Așırı doymamıș katı solüsyon $\rightarrow$ GP bölgeleri $\rightarrow \eta^{\prime} \rightarrow \eta$

olarak veya

- Aşırı doymamış katı çözelti $\rightarrow$ GP bölgeleri $\rightarrow \mathrm{T}^{\prime} \rightarrow \mathrm{T}$ 
olarak gerçekleşmektedir [1]. $\eta^{\prime}$ fazı yarı dengeli bir faz, $\eta$ fazı ise dengeli olmayan faz olarak tanımlanmaktadır [7]. Yüksek sıcaklıklarda yaşlandırma işleminde yüksek $\mathrm{Zn:Mg}$ oranlarında hegzagonal $\eta^{\prime}$ fazı oluşurken, düşük $\mathrm{Zn:Mg}$ oranlarında $T$ $\left(\mathrm{Al}_{2} \mathrm{Mg}_{3} \mathrm{Zn}_{3}\right)$ fazı oluşabilmektedir.

7XXX seri alüminyum alaşımları yüksek yaşlandırılabilme kabiliyeti göstermektedirler [8,9]. Yaşlandırma sıcaklığına ve süresine bağlı olarak değişen yapay yaşlandırma işleminde, malzemenin kullanılacağı yerde, en uygun yaşlandırma parametrelerini tespit edebilmek için pekçok çalışma yapılmıştır [10-14]. Çalışmalardaki temel husus içyapıdaki fazların farklı yaşlandırma sıcaklık ve sürelerinde değişiklik göstermesidir [15]. 7075 serisi alüminyum alaşımında içyapı $\mathrm{Al}$ ve $\mathrm{MgZn}_{2}$ fazlarından oluşmaktadır $[16,17]$. Yapay yaşlandırma işleminde ilk olarak GP bölge içerisinde çekirdeklenmelerin başlaması için 107-120 ${ }^{\circ} \mathrm{C}$ yaşlandırma sıcaklıkları olması gerekmektedir. İkinci aşama ise $160-170{ }^{\circ} \mathrm{C}$ 'de $M g Z n_{2}$ çökeltilerinin oluşmaya başlamasıdır. $\mathrm{Bu}$ çökelti parçacıklarının oluşumu T6 temperine göre mukavemetin yaklaşık \%15 düşmesine neden olmaktadır [18]. Yaşlandırma süresi arttıkça, çökeltiler büyüyerek dislokasyon hareketlerini engellemeye başlayarak mukavemetin artışına sebep olurlar. Ancak çökelti boyutunun kritik bir değeri aşması halinde ise artık taneler aşırı kabalaştığ 1 için dislokasyon hareketleri kolaylaşmakta ve mukavemetin düşmesine neden olmaktadır. $\eta^{\prime}$ fazı mukavemeti artırırken [12, 19-21], $\eta$ fazı ise düşürmektedir [20, 22, 23]. Yaşlandırma sıcaklığının artması ise akma mukavemetini düşüren bir etkiye sahiptir [24].

7075-T6 alüminyum alaşımında farklı çözeltiye alma sıcaklıkları $\left(420,450,480,510,530^{\circ} \mathrm{C}\right)$ ve farklı yaşlandırma sıcaklıklarında $\left(107,121,165^{\circ} \mathrm{C}\right)$ yapay yaşlandırma uygulanmış ve mukavemet değerleriyle sertlik değerleri arasında bir uyum olduğu gösterilmiştir [25]. Farklı sıcaklıklarda çözeltiye alma işlemleri uygulanıp yapay yaşlandırma uygulanan malzemede $\mathrm{MgZn}_{2}$ fazı belirlenmiştir [26]. Dolayısıyla yaşlandırmadaki etken parametrelerden biriside numunelerin soğuma hızıdır. Çünkü hızlı soğutma yapılırsa, $\mathrm{Mg}$ ve $\mathrm{Zn}$ atomlarının çözünmeleri için yeterli zaman olmadığından $\mathrm{MgZn}_{2}$ fazı oluşmamaktadır $[4,26]$. Yapılan bir araştırmada $150^{\circ} \mathrm{C}$ yaşlandırma sıcaklığından sonra $M g Z n_{2}$ fazlarının görülmeye başlandığı ve sıcaklık yükseldikçe fazların oranlarının arttığı gösterilmiştir. Ancak $150{ }^{\circ} \mathrm{C}$ 'den sonra önemli oranda mukavemet kaybı olmuştur. Sebebi ise GP, $\eta^{\prime}$ ve $\eta$ faz dönüşümleridir [23]. $190{ }^{\circ} \mathrm{C}$ 'nin üstünde $\eta^{\prime}$ fazı azalmaya başlamaktadır [12]. 145,165 ve $185^{\circ} \mathrm{C}$ sıcaklıklarında $\eta^{\prime}$ fazı çoğunlukla olmak üzere yapıda $\eta$ fazı da mevcuttur [27]

Bilindiği üzere otomotiv endüstrisinde malzemeler şekillendirildikten sonra $170-200{ }^{\circ} \mathrm{C}$ sicaklıklar arasında boya firınlama işlemine tabi tutulmaktadır [28]. Bu nedenle bu sıcaklık değerleri otomotiv sacları için her zaman dikkat çekici olmaktadır. GP-I fazının fırınlama sertleşmesine katkıda bulunduğu görülmektedir [29]. 6111 seri alüminyum alaşımlarında $\% 2$ ve $\% 5$ ön gerinme uygulanan numunelere 150 ve $170{ }^{\circ} \mathrm{C}$ sicakliklarda 20 ve 30 dakika boyunca firınlama yapıldığında yüksek ön gerinme halinde daha yüksek akma mukavemeti elde edildiği görülmektedir.
Bunun nedeni ise ön gerinmenin artması halinde pekleşmenin de artmasından dolayıdır [30]. 7075 alüminyum alaşımına \%8 ön gerinme uygulanıp $140{ }^{\circ} \mathrm{C}$ sıcaklıklarda farklı sürelerde yaşlandırma işlemi yapıldığında ön gerinmenin çökelme sertleşmesinde önemli bir katkısı olduğu görülmektedir [31]. Mg-Zn-Y alaşımı, \%3-5 ön gerinme işlemiyle $150^{\circ} \mathrm{C}$ yaşlandırma sıcaklığında farklı sürelerde yaşlandırmaya tabi tutulmuş ve ön gerinmenin artmasıyla mukavemet ve sertlik değerleri de artmıştır [32]. Malzemelerin içyapı özelliklerinin incelenmesinde X 1 şını kırınımı (XRD) pik profili analizi, Geçirimli Elektron Mikroskobu (TEM) incelemelerinin güçlü bir alternatifidir [33]. Bütün malzemelerin mekanik ve fiziksel özellikleri içyapıları ile doğrudan ilişkilidir. Bu yüzden Rietveld analizinin kullanımı gittikçe yaygınlaşmaktadır. Bu yöntem bir eğri uydurma yöntemi olup, eğri altındaki alanların pik değerlerin ölçülmesi gerektiğinde başvurulan bir yöntemdir. İleriki bölümlerde kullanım şekli anlatılacaktır.

Bu çalışmada,AA 7075 sac numunelerine farklı̈̈ngerinmelerle şekillendirilmiş numunelere farklı yaşlandırma sıcaklıkları uygulayarak mekanik özelliklerinin değişimi incelenmiştir. 30 dakika süresince farklı yaşlandırma sıcaklıklarında, farklı ön gerinmelerin mekanik özelliklere etkileri tespit edilmiştir.

\section{MALZEME VE YÖNTEM}

2 mm kalınlığında 7075-T6 malzemesine, \%2, 4 ve 6 ön gerinmeler uygulanmıştır. Ön gerinme (ön deformasyon), şekil değiştirme kontrollü olarak yapılan bir çekme deney cihazında gerçekleştirilmiştir. Müteakip başlıklarda çekme deneyine ilişkin bilgiler detaylıca verilmiştir. Daha sonra ön gerinme uygulanmayan ve uygulanan numuneler $500{ }^{\circ} \mathrm{C}$ s1caklıkta 2 saat süreyle çözeltiye alınmıştır. Süre bitiminde en fazla 10 saniye içerisinde oda sıcaklığındaki suda soğutma işlemi gerçekleştirilmiştir. Ardından numunelere 30 dakika boyunca 120,160 ve $200{ }^{\circ} \mathrm{C}$ sıcaklıklarında yapay yaşlandırma işlemi uygulanmıştır. Yapay yaşlandırması tamamlanmış olan numunelere $25 \mathrm{~mm} /$ dak deformasyon hızında çekme ve eğme deneyleri yapılmıştır. Mikroyapı incelemesi için XRD ve optik mikroskop kullanılmıştır. Kullanılan malzemenin kimyasal bileşimi Tablo 1'de verilmiştir.

Tablo 1. 7075 alüminyum alaşımının kimyasal bileşimi

\begin{tabular}{|l|l|l|l|l|l|l|l|l|}
\hline $\mathrm{Si}$ & $\mathrm{Fe}$ & $\mathrm{Cu}$ & $\mathrm{Mn}$ & $\mathrm{Mg}$ & $\mathrm{Cr}$ & $\mathrm{Zn}$ & $\mathrm{Ti}$ & $\mathrm{Ti}+\mathrm{Zr}$ \\
\hline 0,07 & 0,12 & 1,5 & 0,02 & 2,6 & 0,18 & 5,8 & 0,05 & 0,08 \\
\hline
\end{tabular}

Deney numuneleri ASTM-E8 standardına göre hadde yönünde su jetiyle kesilerek hazırlanmıştır. Geri esneme deyinde $60^{\circ} \mathrm{V}$ kalıp kullanılmıştır (Şekil 1). Çekme ve eğme deneyleri Shimadzu Autograph $100 \mathrm{kN}$ çekme cihazında üçer tekrarlı olarak yapılmıştır. Numunelerde meydana gelen uzamalar video tipi ekstansometre ile, geri esneme miktarı ise görüntü işleme teknikleri kullanarak ölçülmüştür. 


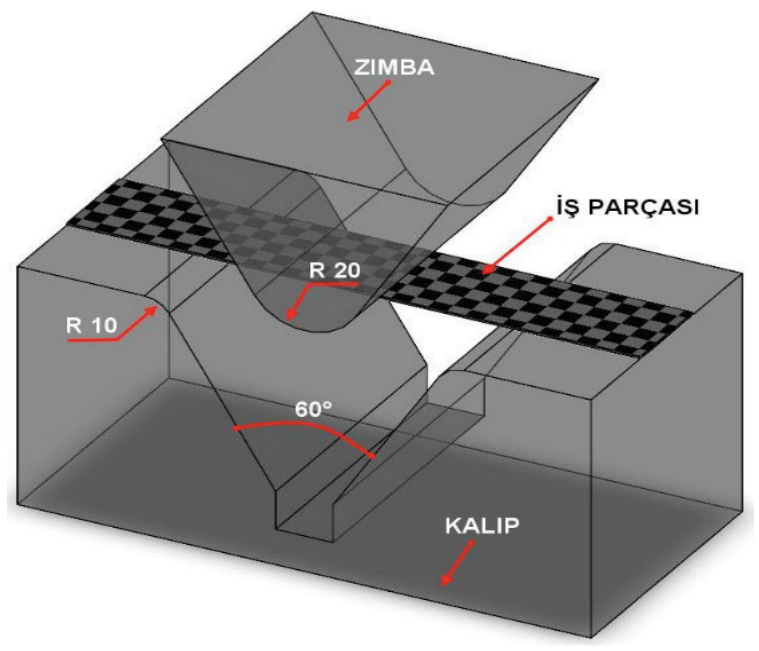

Şekil 1. $60^{\circ} \mathrm{V}$ kalıpta eğme deney düzeneği

Malzemelerin özellikleri, kimyasal bileşimlerine ve içyapıyı oluşturan fazlara göre değişiklik göstermektedir. Fazlar, malzemelerin sünek veya kırılgan olması gibi birçok özellikte belirleyici olmaktadır. Malzemelerde yer alan fazları kolaylıkla belirleyebilmek için XRD yöntemi tercih edilmektedir. X ışınları, malzemelerin atomik ve moleküler yapısının incelenmesinde ve sinıflandırılmasında yaygın olarak tercih edilmektedir. Son zamanlarda Rietveld yöntemiyle malzemelere ait birçok bilgi XRD grafiklerinden elde edilmektedir [34-39]. Rietveld yönteminin temeli ise bir takım matematiksel modeller kullanarak eğri uydurma prensibine dayanmaktadır. Her ne kadar, grafiklere bakıldığında noktalarlar arası çizgilere aldanarak, mevcut bir eğrinin varlığından bahsetmek kolay gibi gözükse de esasen grafiğin sadece noktalar kümesi olduğunu unutmamak gerekir. Böylesi noktalardan oluşan kümenin en uygun fonksiyon ile modellenerek istenen işlemlerin (altta kalan alan, uzunluk, yarı genişlik, ortalama değer vs...) yapılabilmesi mümkün olabilecektir. Rietveld yöntemi de eğri uydurmak ve bu eğriyle ilgili geometrik işlemleri yaparak, böylesi işlemleri mümkün kılmaktadır. Rietveld yöntemi kullanarak analiz yapan ücretsiz lisansa sahip bazı programlar şunlardır; MAUD (Material Analysis Using Diffraction) [40], Profex (Rietveld Refinement) [41] ve FullProf Suite (Structure Profile Refinement) [42]. Bu çalışmada MAUD ve Profex programlarından faydalanılmıştır. Şekil 2'de ideal bir XRD grafiği verilmiştir. Kafes parametreleri, kristal yapı, faz oranları, kristal yapı kusurları, kalıntı gerilmeler ve düzlemler arası mesafe vb. bilgiler bu grafikten rahatlıkla elde edilebilmektedir.

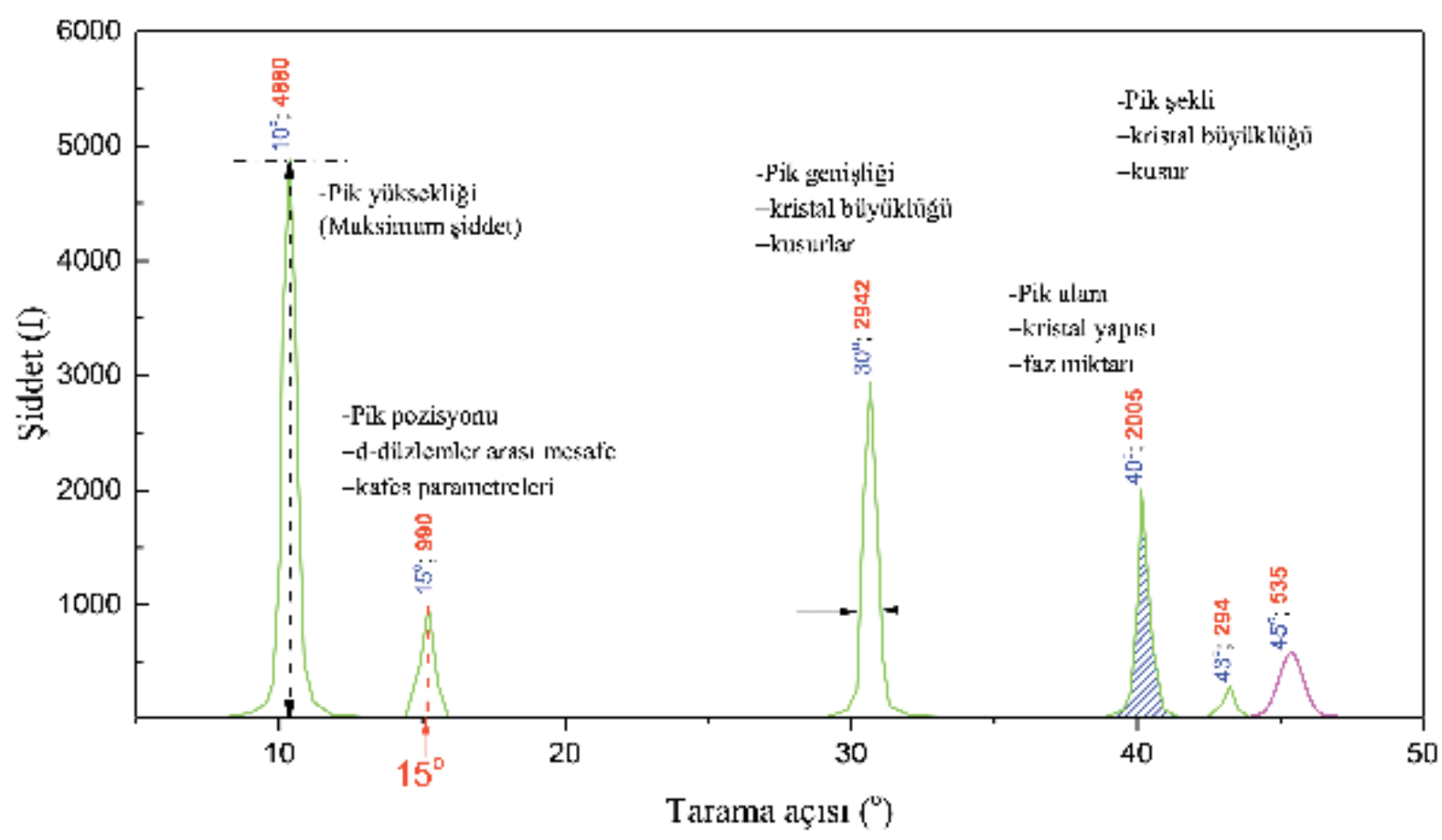

Şekil 2. İdeal bir XRD grafiği ve piklerden bilgilerin elde edilmesi [43] 


\section{BULGULAR ve TARTIŞMA}

\subsection{XRD Analizleri}

Şekil 3'de PANalytical marka XRD cihazı ile 35 dereceden 80 dereceye kadar 0,05 derece/dk hızla tarama yapılarak elde edilen $\mathrm{XRD}$ grafiği verilmiştir. $\mathrm{XRD}$ analizinde $\mathrm{Cu} \mathrm{K} \alpha$ ışınımı yapan bakır anotlu XRD tüpü kullanılmıştır. Yapılan Rietveld analizine göre yapı $\mathrm{Al}$ ve $\mathrm{MgZn}_{2}$ fazlarından oluşmaktadır. Burada piklerin altında kalan alan fazların oranlarını vermektedir. Piklerin sağa veya sola doğru kaymaları ise oluşan iç gerilmeleri ifade etmektedir.

Yaşlandırma sürelerinin artmasıyla beraber yapıda $\mathrm{MgZn}_{2}$ oluşumu artmaktadır [23, 27]. 120 ve $160^{\circ} \mathrm{C}$ yaşlandırma sıcaklıklarında 30 dakika süresi $\mathrm{MgZn}_{2}$ fazlarının oluşması için yeterli olmamışken, $\mathrm{MgZn}_{2}$ fazı $200^{\circ} \mathrm{C}$ sıcaklıkta oluşmaya başlamıştır. Aynı zamanda ön gerinmenin artmasıla $\mathrm{MgZn} \mathrm{n}_{2}$ fazının hacim oranı arttığı görülmektedir (Şekil 3-6). Faz hacmindeki artış, piklerin altlarında kalan alanların büyümesiyle anlaşılmaktadır. Alan ne kadar büyük ise, fazın miktarı da o kadar fazladır.
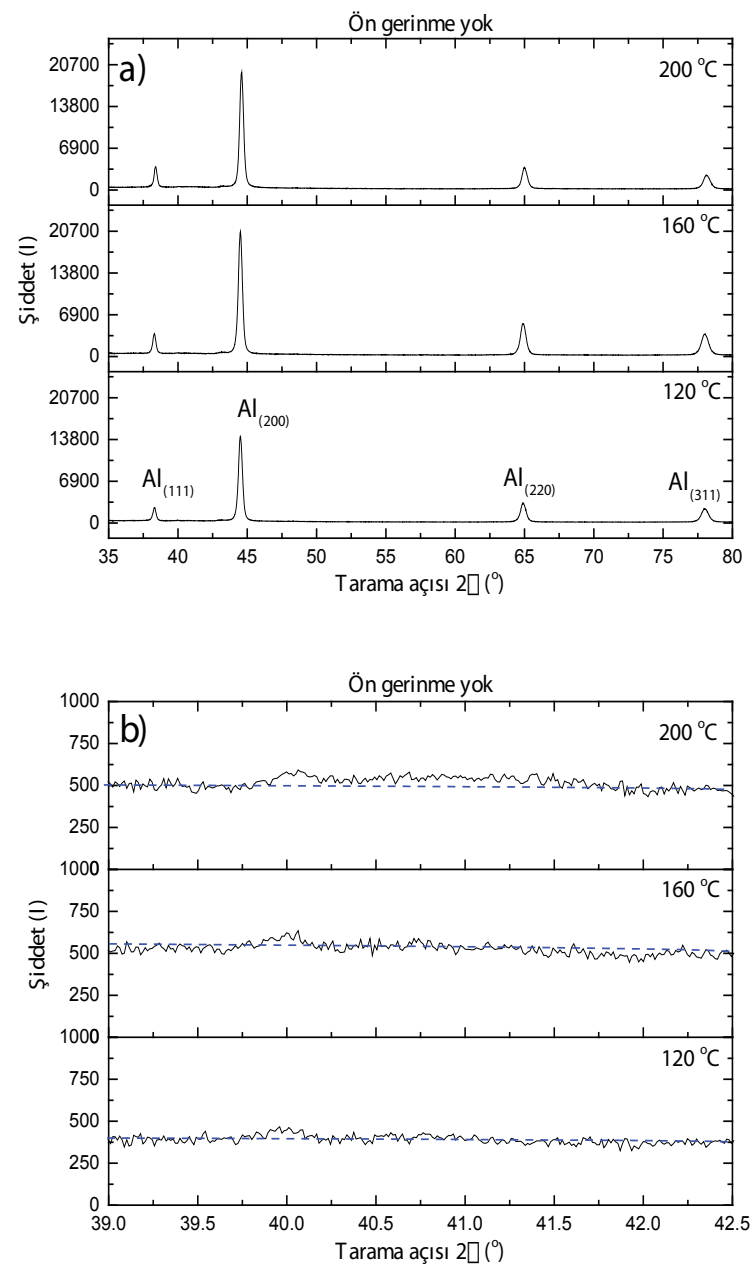

Şekil 3. a) 7075 alüminyum alaşımın farklı sıcaklıklarda 30 dakika yaşlandırma işlemi (Ön gerinme yok), b) yakınlaştırılmış görüntü
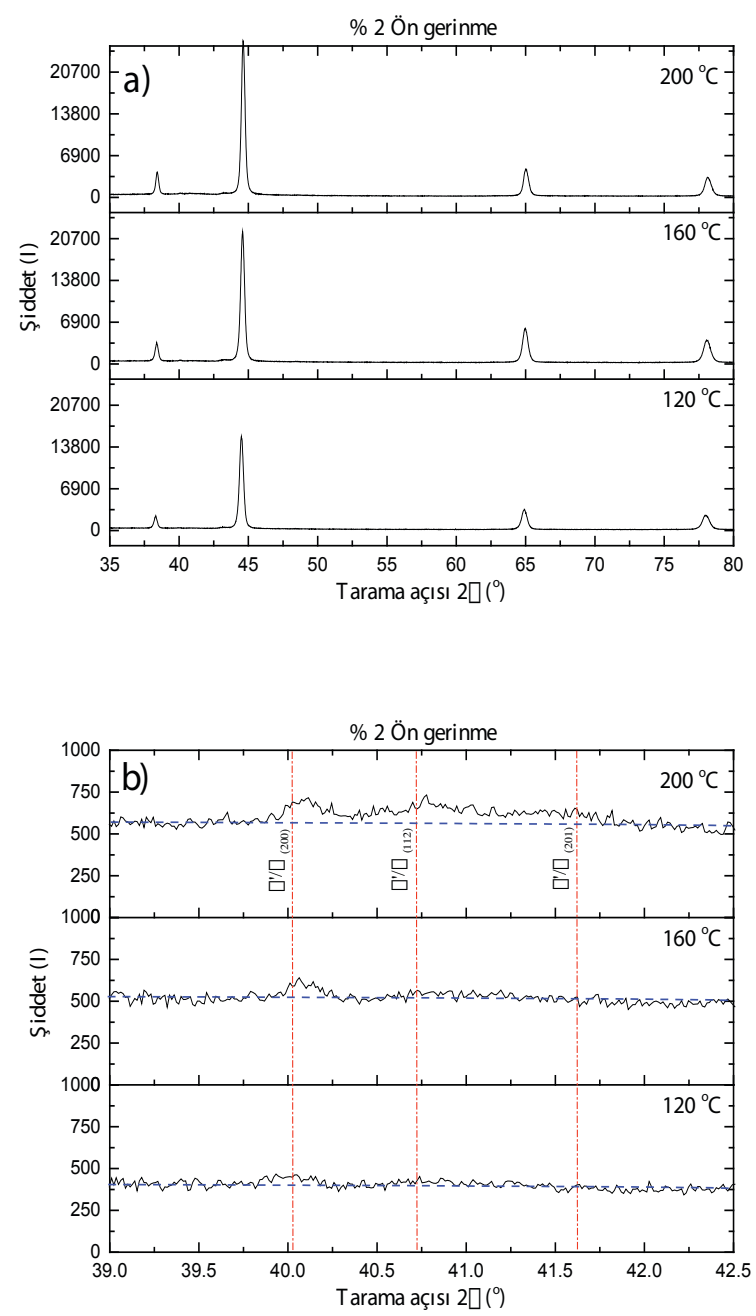

Şekil 4. a) 7075 alüminyum alaşımın farklı sıcaklıklarda 30 dakika yaşlandırma işlemi (\%2 ön gerinme), b) yakınlaştırılmış görüntü

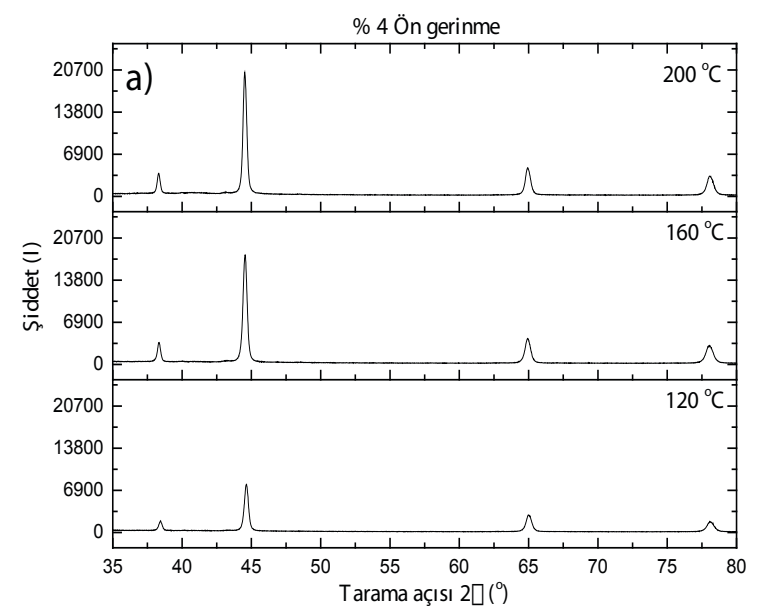




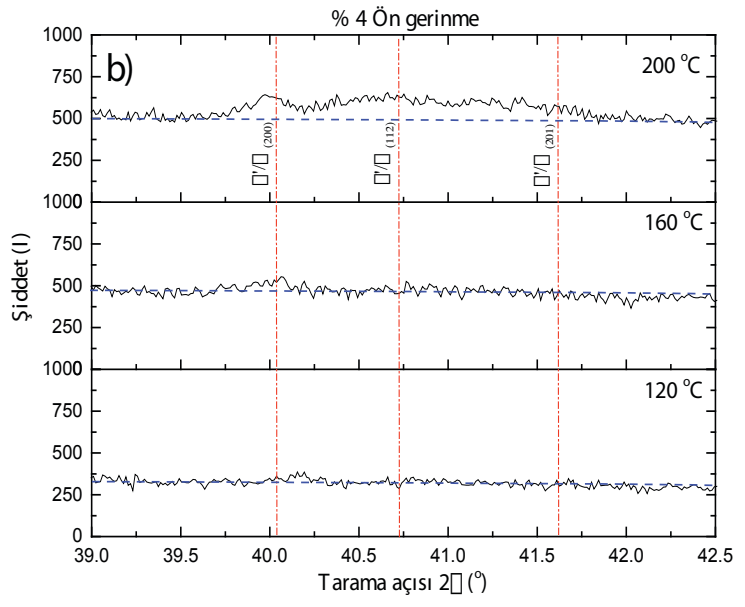

Şekil 5. a) 7075 alüminyum alaşımın farklı sıcaklıklarda 30 dakika yaşlandırma işlemi (\%4 ön gerinme), b) yakınlaştırılmış görüntü
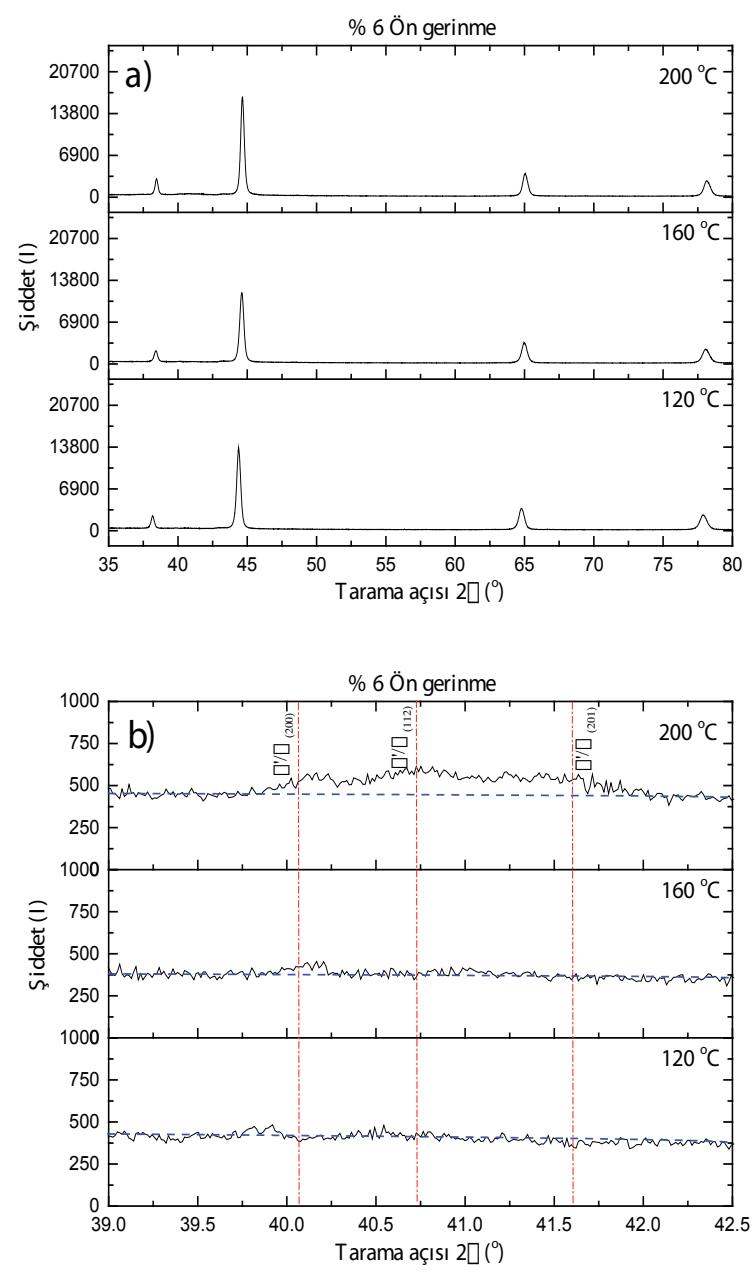

Şekil 6. a) 7075 alüminyum alaşımın farklı sıcaklıklarda 30 dakika yaşlandırma işlemi (\%6 ön gerinme), b) yakınlaştırılmış görüntü
XRD grafiklerinden malzemelere ait birçok özellik elde edilmektedir. Malzeme deformasyona maruz kaldığında içyapısı ve dolayısıyla da XRD grafiği değişmektedir. Örneğin malzemeye bir ön gerinme uygulandığı zaman XRD pikleri sağa veya sola doğru kaymaktadır. $\mathrm{Bu}$ kayma malzemede iç gerilmelerin oluştuğunu ifade etmektedir. Grafikteki piklerden maksimum yükseklikte olanının, genişliği de malzemenin mukavemetiyle ilişkilidir. XRD pikleriyle ön gerinmelerin etkisi araştırıldığında, pik genişliğinin artmasıyla mukavemet, toplam uzama ve sertlik değerlerinin de arttığ görülmektedir [44]. Ayrıca FWHM (Full width at half maximum - bir maksimum pikin yüksekliğinin yarı değerindeki genişliğinin tam değeri) değeri büyük olunca sertlik yüksek çıkmaktadır [45]. XRD grafiklerinin incelememesinde genellikle Rietveld analizi kullanılmaktadır. Rietvel yönteminde ise Gauss, Gaussian, lorentz, Voigt vb... denklemler ile eğri uydurma yapılmaktadır [43]. Bu eğri uydurma sonucu pik genişliğinin hesaplanmasını Şekil 7 göstermektedir.

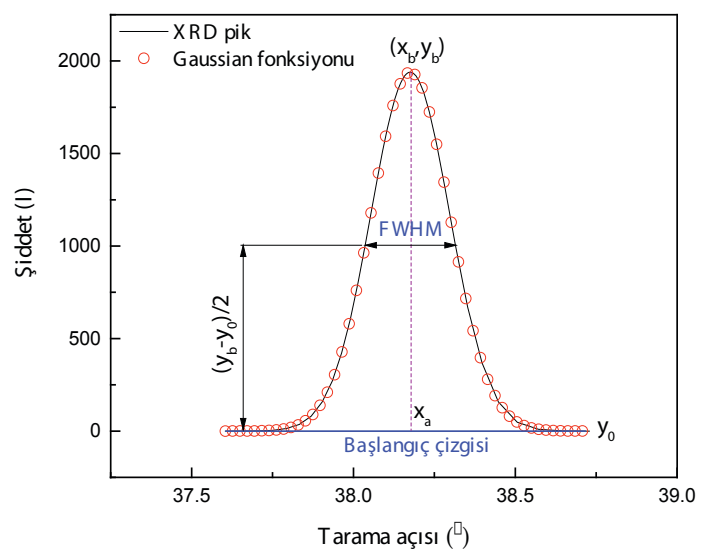

Şekil 7. Rietveld analiziyle pik genişliği bulma (FWHM)

Şekil 8 incelendiğinde, pik genişliğinin değiş̧imi görülecektir. Ön gerinmenin artmasıyla beraber 120 ve $160^{\circ} \mathrm{C}$ yaşlandırma sıcaklıklarında pik genişlikleri artmaktadır. $200{ }^{\circ} \mathrm{C}$ yaşlandırma sıcaklığında ise pik genişlikleri azalmaktadır.

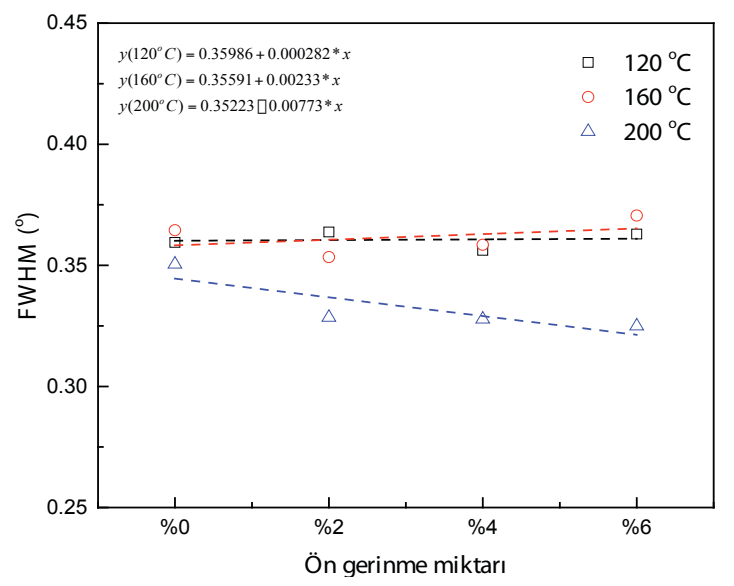

Şekil 8. Sicaklık ve ön gerinmeye göre pik genişliğinin değişimi 
Ön gerinme oranına göre tane büyüklüğünün değişimi de Şekil 9'da gösterilmiştir. Şekil üzerindeki noktalar Profex programı yardımıyla XRD grafiğinden elde edilmiştir. Bunun temeli ise Scherrer denklemine dayanmaktadır [46]. Literatürde birçok çalışmada XRD ve TEM yardımıyla elde edilen değerler karşılaştırılarak kullanılmaktadır [47-50]. 120 ve $160^{\circ} \mathrm{C}$ yaşlandırma sıcaklığında ön gerinme ile taneler ufak kalırken, $200{ }^{\circ} \mathrm{C}$ yaşlandırma sıcaklığında ön gerinme ile taneler kabalaşmaktadır.

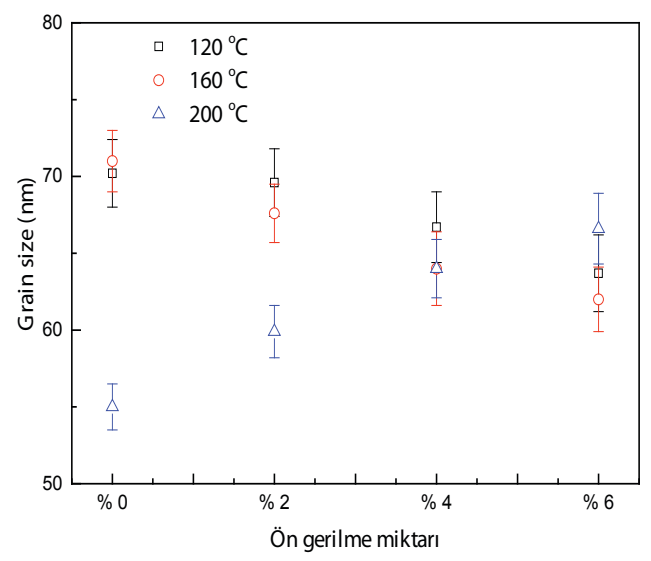

Şekil 9. Tane büyüklüğünün ön gerinmeye göre değişimi

\section{2 Çekme Deneyleri}

Farklı ön gerinmeler uygulanmış numunelerin, 30 dakika yaşlandırma süresinde farklı sıcaklıklarda yaşlandırma işlemi uygulanmasına müteakip, elde edilen yaşlandırılmış numunelere, $25 \mathrm{~mm} /$ dak deformasyon hızında çekme deneyleri uygulanmış ve sonuçları Şekil 10-13' de verilmiştir. Ön gerinme uygulanmayan numunelerde 120 ve $160^{\circ} \mathrm{C}$ yaşlandırma sıcaklıklarında sonuçlar hemen hemen aynıdır. $200{ }^{\circ} \mathrm{C}$ yaşlandırma sıcaklığında ise mukavemet artmış, birim deformasyon değeri düşmüştür. Farklı ön gerinme uygulanan numunelerin tamamında ise 120 ve $160^{\circ} \mathrm{C}$ yaşlandırma sıcaklıklarında Portevin Le Chatelier etkisi görülürken $200{ }^{\circ} \mathrm{C}$ yaşlandırma sıcaklığında ise bu etki ortadan kalkmaktadır. Çünkü bu sıcaklıklarda artık dislokasyon hareketleri bir kararlı duruma ulaşmaktadırlar. Portevin Le Chatelier etkisi olarak adlandırılan durum, plastik deformasyon eğrisinde sürekli bütün eğri boyunca dalgalanma olması halidir. Sebebi, dislokasyon hareketinin ilerleme-durdurulma-ilerleme şeklinde dinamik bir davranış halinde olmasıdır. $\mathrm{Bu}$ durum, artan sıcaklıklarda kendisini gösterir zira akma mukavemeti azalır. Böylece dislokasyonların serbest hareketi kolaylaşır. Dislokasyon tam ilerliyorken, yapı atomları bu dislokasyonun önüne geçmekte, hareketini kısıtlamakta ve nihayetinde de mukavemette bir artış meydana gelmektedir.

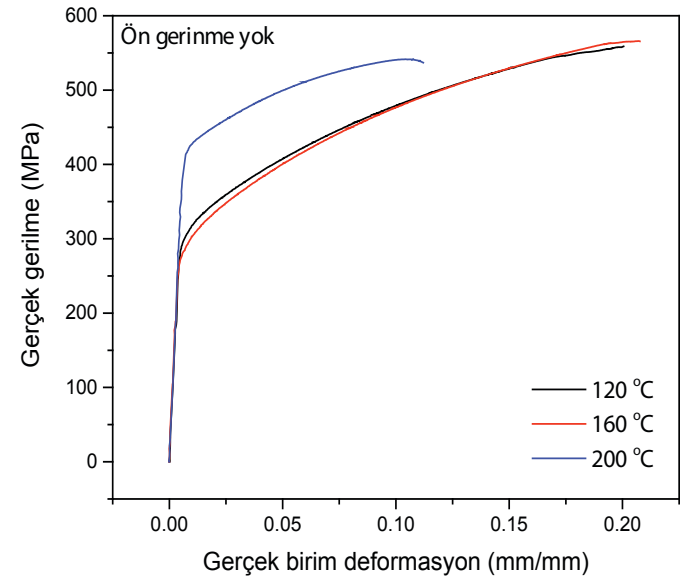

Şekil 10. Ön gerinme uygulanmamış numunelerin farklı sıcaklıklardaki gerilme birim deformasyon eğrisi
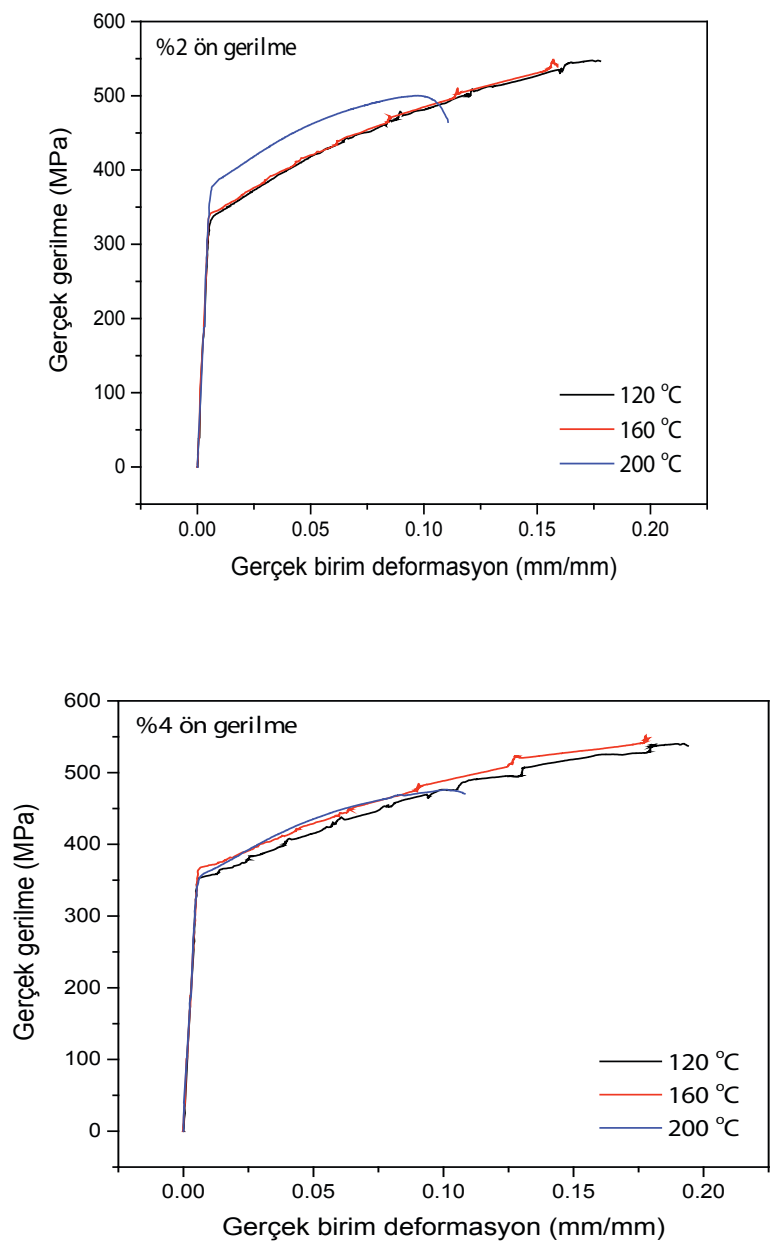

Şekil 12. \%4 Ön gerinme uygulanmış numunelerin farklı sıcaklıklardaki gerilme birim deformasyon eğrisi 


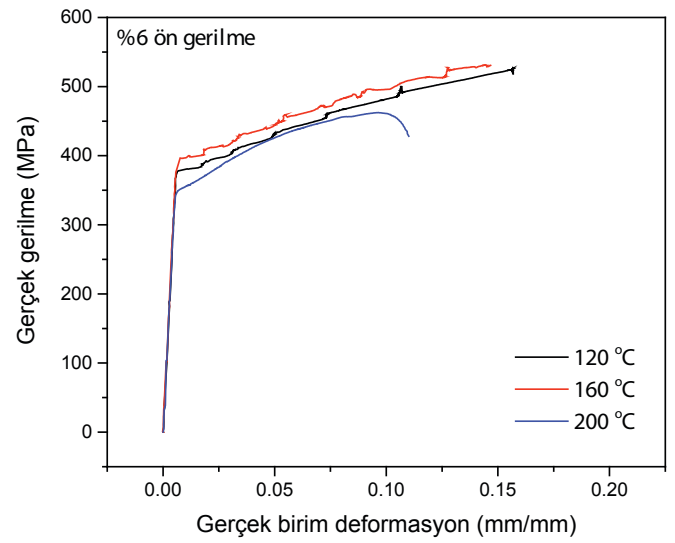

Şekil 13. \%6 Ön gerinme uygulanmış numunelerin farklı sıcaklıklardaki gerilme birim deformasyon eğrisi

120 ve $160^{\circ} \mathrm{C}$ yaşlandırma sıcaklıklarında ön gerinmenin artmasıyla akma mukavemeti artarken, çekme mukavemeti ve toplam uzama miktarı düşmektedir. $200{ }^{\circ} \mathrm{C}$ yaşlandırma sıcaklığında ise ön gerinmenin artmasıyla akma ve çekme mukavemeti düşerken, toplam uzama miktarında bir değişiklik meydana gelmemiştir (Şekil 14-16).

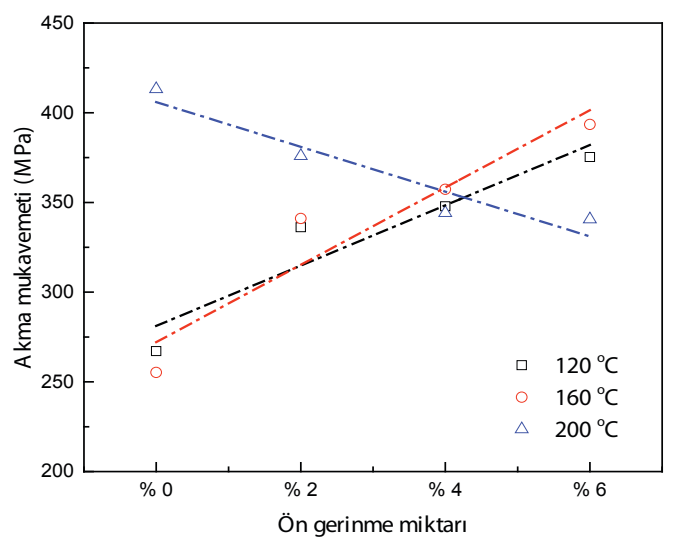

Şekil 14. Farklı sıcaklıklarda farklı ön gerinme miktarlarının akma mukavemetine etkisi

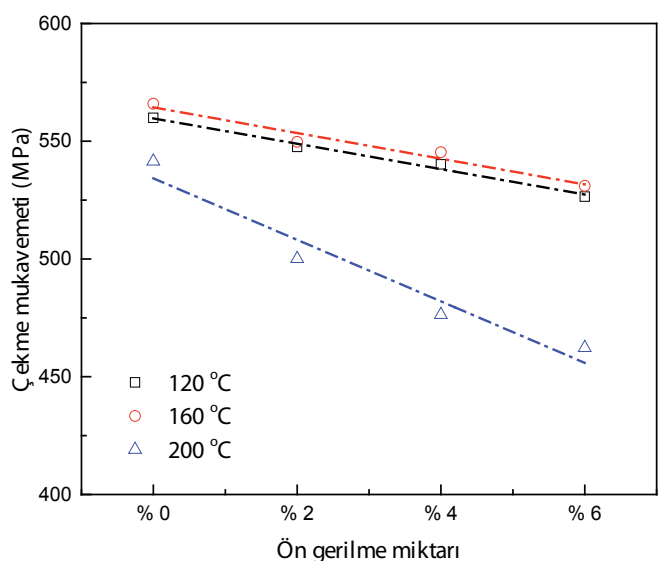

Şekil 15. Farklı sıcaklıklarda farklı ön gerinme miktarlarının çekme mukavemetine etkisi

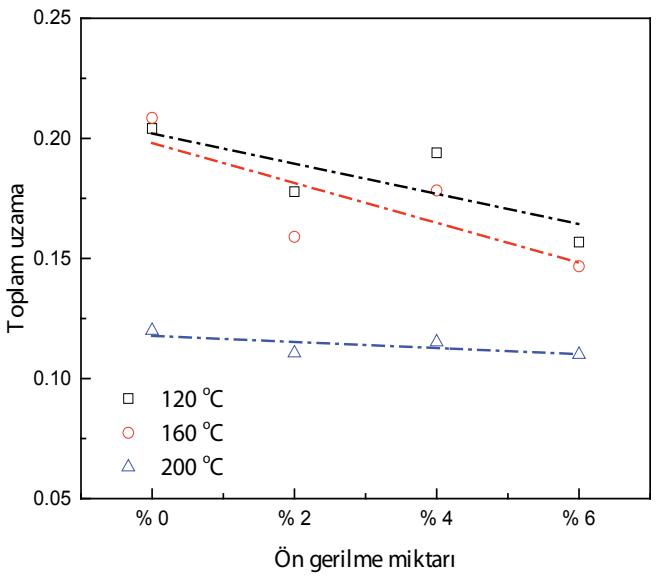

Şekil 16. Farklı sıcaklıklarda farklı ön gerinme miktarlarının toplam uzamaya etkisi

\subsection{Geri Esneme Deneyleri}

Geri esneme deneylerinde de çekme deneylerinde olduğu gibi $25 \mathrm{~mm}$ /dak deformasyon hızı kullanılmıştır. Zımba bükme işlemini için ilerleme yapmış ancak sac üzerinde herhangi bir ezme işlemi yapılmamıştır. Zımba, mesafe kontrollü olarak hareket ettirilmiştir. Bükme işlemi bittikten sonra otomatik olarak tekrar eski konumuna gelmektedir. 120 ve $160{ }^{\circ} \mathrm{C}$ 'lerde yaşlandırılan numunelere uygulanan bükme neticesinde, ön gerinmenin artmasıyla beraber geri esneme miktarının da arttığ́1 gözlemlenmiştir. Ancak $200{ }^{\circ} \mathrm{C}$ 'de yaşlandırılmış numuneler üzerine yapılan deneylerde geri esneme düşmektedir (Şekil 17). Literatürde de benzer şekilde artan yaşlandırma s1caklığıyla geri esnemenin azaldığı belirtilmiştir [51].

Geri esneme miktarını etkileyen parametrelerden bir diğeride akma mukavemetidir. Şekil 14'de görüldüğü gibi akma mukavemetinin artması geri esnemeyi artırmaktadır. Zira ön gerinme miktarı arttıkça, akma mukavemeti artmaktadır. $\mathrm{Bu}$ durum $200{ }^{\circ} \mathrm{C}$ ye kadar olan sıcaklıklarda geçerlidir. $200{ }^{\circ} \mathrm{C}$ den sonrasında ise tersi durum oluşmaktadır.

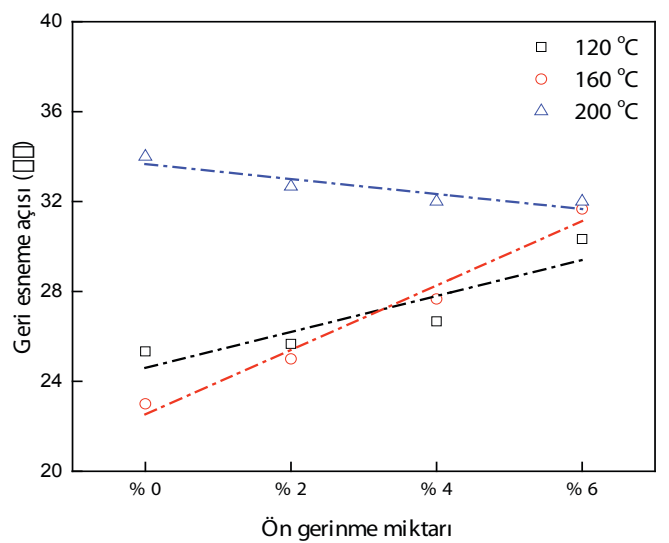

Şekil 17. Farklı yaşlandırma sıcaklık ve sürelerin geri esnemeye etkisi 


\section{IV.SONUCLLAR}

$\mathrm{Bu}$ çalışmada havacılık ve uzay sanayinde yoğunlukla tercih edilen 7075 serisi alüminyum alaşımında yaşlandırma işleminde ön gerinmenin mekanik özelliklere etkisi araşt1rılmıştır. Özellikle otomotiv sektöründe şekillendirilmiş parçalar boyama işleminden sonra $120-200{ }^{\circ} \mathrm{C}$ sıcaklıkları arasında farklı sürelerde (10-30 dk.) firınlama işlemine tabi tutulmaktadır. Böylece yaşlandırılabilen bir malzeme kullanıldığı zaman, firınlama işleminde hiçbir işlem yapmadan mukavemet değerlerinde bir artış olacaktır. Bu kapsamda bu çalışmada da yaşlandırma sıcaklığı olarak 120, 160 ve $200^{\circ} \mathrm{C}$ olarak tercih edilmiştir. Yaşlandırma süresi ise $30 \mathrm{da}-$ kika seçilmiştir. Numunelere farklı ön gerinmeler uygulayarak, ön gerinmenin yaşlandırmadaki etkisi detaylı olarak incelenmiştir. Yapılan incelemeler sonucunda 120 ve $160{ }^{\circ} \mathrm{C}$ yaşlandırma sıcaklıklarında $\mathrm{MgZn}_{2}$ çökeltisi yokken ön gerinme uygulanmasıyla da oluşmamıştır. $200{ }^{\circ} \mathrm{C}$ sıcaklığında ise 30 dakika yaşlandırma süresinde $\mathrm{MgZn}_{2}$ çökeltisi oluşmaya başlamış ve ön gerinmenin artmasıyla beraber hacim olarak $\mathrm{MgZn}_{2}$ fazında artış görülmüştür. $\mathrm{MgZn}_{2}$ çökeltisinin oluşmasından sonra, sıcaklığa bağlı oılarak yapıda yumuşama meydana gelmektedir. Ön gerinmenin artmasıly 120 ve $160{ }^{\circ} \mathrm{C}$ yaşlandırma sıcaklıklarında pekleşmenin etkisiyle akma mukavemeti artarken, $200{ }^{\circ} \mathrm{C}$ yaşlandırma sıcaklığında $\mathrm{MgZn}_{2}$ çökeltisi nedeniyle akma mukavemeti düşmeye başlamıştır. Çekme mukavemeti de aynı şekilde bütün yaşlandırma sıcaklıklarında düşerken toplam uzama miktarı ise $200{ }^{\circ} \mathrm{C}$ yaşlandırma sıcaklığında neredeyse hiç değişmemiştir. Geri esneme sonuçlarına baktığımız zaman ise akma mukavemetiyle benzer özellikleri göstermektedir. 120 ve $160^{\circ} \mathrm{C}$ yaşlandırma sıcaklıklarında Portevin-Le Chatelier etkisi görülmüş, $200^{\circ} \mathrm{C}$ yaşlandırma sıcaklığında ise beklenildiği üzere bu etki ortadan kaybolmuştur.

\section{TEŞEKKÜR}

Bu çalışma, Ahi Evran Üniversitesi Bilimsel Araştırma Projeleri Koordinasyon Birimi'nce desteklenmiştir. Proje Numaras1: MMF.A3.17.001. ("This work was supported by the Ahi Evran University Scientific Research Projects Coordination Unit. Project Number: MMF.A3.17.001.”). Desteklerinden dolayı Bilimsel Araştırma Projeleri Koordinasyon Birimi'ne teşekkürlerimizi sunarız.

\section{KAYNAKLAR}

[1] Vasudevan, A. K., ve Doherty, R. D. (1989). Aluminum Alloys - Contemporary Research and Applications: Contemporary Research and Applications (Vol. 31). England: Elsevier

[2] Mondal, C., ve Mukhopadhyay, A. K. (2005). On the nature of $\mathrm{T}(\mathrm{Al} 2 \mathrm{Mg} 3 \mathrm{Zn} 3)$ and $\mathrm{S}(\mathrm{Al} 2 \mathrm{CuMg})$ phases present in as-cast and annealed 7055 aluminum alloy. Materials Science and Engineering: A, 391(1), 367-376.

[3] Lalpour, A., Soltanipour, A., ve Farmanesh, K. (2015, 11,12 November 2015). Effect of Friction Stir Processing on the Microstructure and Superplasticity of 7075 Aluminum Alloy. Paper presented at the 5th International Biennial Conference on Ultrafine Grained and Nanostructured Materials (UFGNSM15) Tehran, Iran.

[4] Fan, X.-G., Jiang, D.-M., Meng, Q.-C., Zhang, B.-Y., ve Tao, W. (2006). Evolution of eutectic structures in Al- $\mathrm{Zn}-\mathrm{Mg}-\mathrm{Cu}$ alloys during heat treatment. Transactions of Nonferrous Metals Society of China, 16(3), 577-581.

[5] Lim, S. T., Eun, I. S., ve Nam, S. W. (2003). Control of equilibrium phases (M, T, S) in the modified aluminum alloy 7175 for thick forging applications. Materials Transactions, 44(1), 181-187.

[6] Binesh, B., ve Aghaie-Khafri, M. (2016). Phase evolution and mechanical behavior of the semi-solid SIMA processed 7075 aluminum alloy. Metals, 6(3), 42.

[7] Ozyurek, D., Yilmaz, R., ve Kibar, E. (2012). The effects of retrogression parameters in RRA treatment on tensile strength of 7075 aluminium alloys. Journal of the Faculty of Engineering and Architecture of Gazi University, 27(1), 193-203.

[8] Polmear, I. (1996). Recent developments in light alloys. Materials Transactions, JIM, 37(1), 12-31.

[9] Hunsicker, H. (1976). Development of Al-Zn-Mg-CU alloys for aircraft. Philosophical Transactions for the Royal Society of London. Series A, Mathematical and Physical Sciences, 359-376.

[10] Emani, S., Benedyk, J., Nash, P., ve Chen, D. (2009). Double aging and thermomechanical heat treatment of AA7075 aluminum alloy extrusions. Journal of Materials Science, 44(23), 6384-6391.

[11] Karaaslan, A., Kaya, I., ve Atapek, H. (2007). Effect of aging temperature and of retrogression treatment time on the microstructure and mechanical properties of alloy AA 7075. Metal Science and Heat Treatment, 49(9), 443-447.

[12] Park, J., ve Ardell, A. (1983). Microstructures of the commercial $7075 \mathrm{Al}$ alloy in the T651 and T7 tempers. Metallurgical and Materials Transactions A, 14(10), 1957-1965.

[13] Tash, M. M., ve Alkahtani, S. (2015). Aging and Mechanical Behavior of Be-Treated 7075 Aluminum Alloys. Aging, 1, 7395.

[14] Joshi, A., Shastry, C., ve Levy, M. (1981). Effect of heat treatment on solute concentration at grain boundaries in 7075 aluminum alloy. Metallurgical Transactions A, 12(6), 10811088.

[15] Viana, F., Pinto, A. M. P., Santos, H. M. C., ve Lopes, A. B. (1999). Retrogression and re-ageing of 7075 aluminium alloy: microstructural characterization. Journal of Materials Processing Technology, 92-93, 54-59. 
[16] Pastor, A., ve Svoboda, H. G. (2013). Time-evolution of heat affected zone (HAZ) of friction stir welds of AA7075-T651. Journal of Materials Physics and Chemistry, 1(4), 58-64.

[17] Oskouei, R. H., Barati, M. R., ve Ibrahim, R. N. (2016). Surface characterizations of fretting fatigue damage in aluminum alloy 7075-T6 clamped joints: the beneficial role of Ni-P coatings. Materials, 9(3), 141.

[18] Fontana, M. G., ve Stactile, W. (1970). Corrosion Science and Technology. Plenum Press, London, 1, 149.

[19] Park, J. K., ve Ardell, A. J. (1989). Correlation between microstructure and calorimetric behavior of aluminum alloy 7075 and $\mathrm{Al} \cdot \mathrm{Zn} \cdot \mathrm{Mg}$ alloys in various tempers. Materials Science and Engineering: A, 114(Supplement C), 197-203.

[20] Chen, J., Zhen, L., Yang, S., Shao, W., ve Dai, S. (2009). Investigation of precipitation behavior and related hardening in AA 7055 aluminum alloy. Materials Science and Engineering: A, 500(1), 34-42.

[21] Güleryüz, K., ve Kaçar, R. (2011). Deformasyon Yaşlanmastnın AA7075 Alüminyum Alaşımının Mekanik Özelliklerine Etkisinin Incelenmesi. Paper presented at the 6th International Advanced Technologies Symposium (IATS'11).

[22] Porter, D. A., Easterling, K. E., ve Sherif, M. (2009). Phase Transformations in Metals and Alloys, (Revised Reprint). USA: CRC press

[23] Panigrahi, S. K., ve Jayaganthan, R. (2011). Effect of Annealing on Thermal Stability, Precipitate Evolution, and Mechanical Properties of Cryorolled Al 7075 Alloy. Metallurgical and Materials Transactions A, 42(10), 3208-3217.

[24] Polmear, I., ve Couper, M. (1988). Design and development of an experimental wrought aluminum alloy for use at elevated temperatures. Metallurgical and Materials Transactions A, 19(4), 1027-1035.

[25] Clark, R., Coughran, B., Traina, I., Hernandez, A., Scheck, T., Etuk, C., Peters, J., Lee, E. W., Ogren, J., ve Es-Said, O. S. (2005). On the correlation of mechanical and physical properties of 7075-T6 Al alloy. Engineering Failure Analysis, 12(4), 520-526.

[26] Isadare, A. D., Aremo, B., Adeoye, M. O., Olawale, O. J., ve Shittu, M. D. (2013). Effect of heat treatment on some mechanical properties of 7075 aluminium alloy. Materials Research, 16(1), 190-194.

[27] Mahathaninwong, N., Plookphol, T., Wannasin, J., ve Wisutmethangoon, S. (2012). T6 heat treatment of rheocasting 7075 Al alloy. Materials Science and Engineering: A, 532(Supplement C), 91-99.

[28] Kilic, S., Ozturk, F., Sigirtmac, T., ve Tekin, G. (2015). Effects of Pre-strain and Temperature on Bake Hardening of TWIP900CR Steel. Journal of Iron and Steel Research, International, 22(4), 361-365.

[29] Cao, L., Rometsch, P. A., ve Couper, M. J. (2013). Effect of pre-ageing and natural ageing on the paint bake response of alloy AA6181A. Materials Science and Engineering: A, 571(Supplement C), 77-82.
[30] Li, S.-S., Chen, J.-S., Chen, J., Xia, C., ve Zeng, D. (2015). Influence of Pre-strain on the Mechanical Properties of A6111-T4P Sheet with Bake Hardening. Acta Metallurgica Sinica (English Letters), 28(6), 678-683.

[31] Kaçar, R., ve Güleryüz, K. (2015). Effect of Quenching Rate and Pre-strain on the Strain Ageing Behaviors of 7075 Aluminum Alloys. Materials Research, 18, 328-333.

[32] Rosalie, J. M., Somekawa, H., Singh, A., ve Mukai, T. (2013). Effect of precipitation on strength and ductility in a $\mathrm{Mg}-$ $\mathrm{Zn}-\mathrm{Y}$ alloy. Journal of Alloys and Compounds, 550(Supplement C), 114-123.

[33] Ungár, T. (2004). Microstructural parameters from X-ray diffraction peak broadening. Scripta Materialia, 51(8), 777-781.

[34] Moumeni, H., Alleg, S., Djebbari, C., Bentayeb, F. Z., ve Grenèche, J. M. (2004). Synthesis and characterisation of nanostructured FeCo alloys. Journal of Materials Science, 39(16), 5441-5443.

[35] Mehdaoui, S., Benslim, N., Aissaoui, O., Benabdeslem, M., Bechiri, L., Otmani, A., Portier, X., ve Nouet, G. (2009). Study of the properties of CuInSe2 materials prepared from nanoparticle powder. Materials Characterization, 60(5), 451455.

[36] Benslim, N., Mehdaoui, S., Aissaoui, O., Benabdeslem, M., Bouasla, A., Bechiri, L., Otmani, A., ve Portier, X. (2010). $\mathrm{XRD}$ and TEM characterizations of the mechanically alloyed CuIn0.5Ga0.5Se2 powders. Journal of Alloys and Compounds, 489(2), 437-440.

[37] Dini, G., Najafizadeh, A., Monir-Vaghefi, S., ve Ueji, R. (2010). Grain size effect on the martensite formation in a high-manganese TWIP steel by the Rietveld method. Journal of Materials Science \& Technology, 26(2), 181-186.

[38] Karpikhin, A. E., Fedotov, A. Y., Komlev, V. S., Barinov, S. M., Sirotinkin, V. P., Gordeev, A. S., ve Shamrai, V. F. (2016). Structure of hydroxyapatite powders prepared through dicalcium phosphate dihydrate hydrolysis. Inorganic Materials, 52(2), 170-175.

[39] Heiba, Z. K., Mohamed, M. B., ve Wahba, A. M. (2016). Effect of Mo substitution on structural and magnetic properties of Zinc ferrite nanoparticles. Journal of Molecular Structure, 1108, 347-351.

[40] http://maud.radiographema.eu/. (January 2017).

[41] http://profex.doebelin.org/. (January 2017).

[42] https://www.ill.eu/sites/fullprof/. (January 2017).

[43] Kilic, S., ve Ozturk, F. (2016, 26-28 October). Evaluation of Mathematical Models Performances in XRD Analysis for Determination of Volumetric Ratios of Phases. Paper presented at the 1st International Mediterranean Science and Engineering Congress (IMSEC), Adana, Turkey.

[44] Bouras, M., Boumaiza, A., Ji, V., ve Rouag, N. (2012). XRD peak broadening characterization of deformed microstructures and heterogeneous behavior of carbon steel. Theoretical and Applied Fracture Mechanics, 61(Supplement C), 51-56. 
[45] Fu, P., Chu, R., Xu, Z., Ding, G., ve Jiang, C. (2018). Relation of hardness with FWHM and residual stress of GCr15 steel after shot peening. Applied Surface Science, 431(Supplement C), 165-169.

[46] Scherrer, P. (1918). Estimation of the size and internal structure of colloidal particles by means of röntgen. Nachr. Ges. Wiss. Göttingen, 2, 96-100.

[47] Prabhu, Y. T., Rao, K. V., Kumar, V. S. S., ve Kumari, B. S. (2014). X-ray analysis by Williamson-Hall and size-strain plot methods of $\mathrm{ZnO}$ nanoparticles with fuel variation. World Journal of Nano Science and Engineering, 4(01), 21.

[48] Khorsand Zak, A., Abd. Majid, W. H., Abrishami, M. E., ve Yousefi, R. (2011). X-ray analysis of $\mathrm{ZnO}$ nanoparticles by Williamson-Hall and size-strain plot methods. Solid State Sciences, 13(1), 251-256.
[49] Mote, V., Purushotham, Y., ve Dole, B. (2012). Williamson-Hall analysis in estimation of lattice strain in nanometer-sized $\mathrm{ZnO}$ particles. Journal of Theoretical and Applied Physics, 6(1), 6.

[50] Zhao, Y., ve Zhang, J. (2008). Microstrain and grain-size analysis from diffraction peak width and graphical derivation of high-pressure thermomechanics. Journal of applied Crystallography, 41(6), 1095-1108.

[51] Arabi Jeshvaghani, R., Emami, M., Shahverdi, H. R., ve Hadavi, S. M. M. (2011). Effects of time and temperature on the creep forming of 7075 aluminum alloy: Springback and mechanical properties. Materials Science and Engineering: A, 528(29-30), 8795-8799. 